\title{
Conquistar seu tempo através da formação dos ritmos da própria vida ${ }^{1}$
}

\section{Conquérir son temps par la formation des rythmes de sa vie}

\section{Conquering your time through training rhythms of your life}

\author{
Gaston Pineau* \\ Hervé Breton**
}

\begin{abstract}
RESUMO
Se as pesquisas de Gaston Pineau sobre histórias de vida em formação são reconhecidas na Europa e amplamente divulgadas no Brasil, como em outros lugares do mundo, aquelas sobre a relação entre temporalidades e processos de formação são igualmente importantes. O objetivo desta entrevista é apresentar, utilizando uma abordagem genealógica, as etapas pelas quais este trabalho sobre o tempo foi sendo constituído ao longo da pesquisa de Gaston Pineau e, em seguida, examinar as dimensões contributivas destes trabalhos sobre os modos de formação das correntes de autoformação, formação por alternância, formação experiencial e abordagens narrativas e antropoformativas.
\end{abstract}

Palavras-chave: Alternância. Autoformação. Histórias de vida em formação. Temporalidades. Narrativa.

\section{RÉSUMÉ}

Si les recherches de Gaston Pineau sur les histoires de vie en formation sont reconnues en Europe et largement diffusées au Brésil, comme ailleurs dans

11 Traduzido por Camila Aloisio Alves. E-mail: camila.aloisioalves@gmail.com

* Université de Tours. Tours, France. Université Du Québec à Montréal. Montréal, Québec, Canada. E-mail: gaston.pineau@univ-tours.fr - https://orcid.org/0000-0002-0060-0669b

${ }^{* *}$ Université de Tours. Tours, France. E-mail: herve.breton@univ-tours.fr - https://orcid. org/0000-0003-3536-566X 
le monde, ceux sur les relations entre les temporalités et les processus de formation sont tout aussi décisifs. L'enjeu de cet entretien est de présenter, en empruntant une démarche généalogique, les étapes par lesquelles ces travaux sur le temps se sont constitués au fil des recherches de Gaston Pineau, pour ensuite examiner les dimensions contributives de ces travaux sur modes de constitution des courants de l'autoformation, de la formation par alternance, de la formation expérientielle, et des approches narratives et anthropoformatives.

Mots clés: Alternance. Autoformation. Histoires de vie en formation. Temporalités. Récit.

\begin{abstract}
While Gaston Pineau's research on the history of life in adult education is recognised in Europe and widely disseminated in Brazil, as elsewhere in the world, his research on the links between temporalities and training processes is equally crucial. The aim of this interview is to present, using a genealogical approach, the stages through which this research on While Gaston Pineau's research on the history of life in adult education is recognised in Europe and widely disseminated in Brazil, as elsewhere in the world, his research on the links between temporalities and training processes is equally crucial. The aim of this interview is to present, using a genealogical approach, the stages through which this research on temporalities has developed in the course of Gaston Pineau's research, and then to examine the contributory dimensions of this work on the construction of "self-training" paradigms, pedagogical device between professional practices in work situations and formal education courses, the experiential process of vocational education and narrative and anthropoformative approaches.
\end{abstract}

Keywords: Experiential learning. Life stories in training. Temporalities. Narrative.

Hervé Breton: Olá, Professor Gaston Pineau. Esta entrevista compõe o dossiê Educar em Revista que coordeno junto com a Profa. Dra. Maria Amália Cunha, da Universidade Federal de Minas Gerais (UFMG), de Belo Horizonte, Brasil. A revista comporta uma seção de entrevistas, cujo objetivo é pensar a relação entre temporalidade e formação. Como você afirma no artigo que me enviou, "Conjuguer les temporalités pour en faire des rythmes formateurs" (Conjugar temporalidades para torná-las ritmos formativos) publicado na revista Éducation Permanente, $\mathrm{n}^{\circ}$. 217/2018-4 Rythmes et temporalités en formation Ritmos e temporalidades em formação PINEAU, 2018, p. 9-21), trabalhar sobre 
a questão do tempo significa engajar-se em um campo monumental de pesquisa. Antes de começar, gostaria de lhe pedir que nos conte, em algumas palavras, sobre a sua carreira na universidade como professor e pesquisador.

Gaston Pineau: Você está certo em dizer "na universidade", porque em um momento da minha vida eu nem sabia que ela existia. Portanto, vamos ficar na universidade. Eu tinha trinta anos quando tudo começou, em 1968, no Centre Universitaire de Coopération Economique et Sociale - Cuces (Centro Universitário de Cooperação Econômica e Social), em Nancy, França, que estava lançando programas de formação de adultos. Inicialmente, esse centro universitário em Nancy contratou-me como conselheiro de orientação para adultos em 1968.

Em 1969, como havia grandes programas inovadores no Quebec, candidatei-me para a vaga de professor no departamento de educação continuada na Universidade de Montreal, que estava em vias de se transformar em faculdade. Eles me contrataram como responsável de pesquisa. Não havia ainda uma distinção entre professor e pesquisador, Era um status especial. Havia responsáveis de programas e responsáveis de pesquisa. Por isso, fui responsável de pesquisa de 1969 até 1985 aproximadamente.

Em 1985, foi aberta uma vaga na Universidade de Tours, que solicitava um candidato com o perfil na área de alternância e educação. Candidatei-me, pois tinha acabado de realizar meu doutorado com Georges Lerbet, precisamente sobre "Tempo e contratempos na formação". Fui contratado em 1985 ou 1986. Eu fiquei lá até minha aposentadoria em 2007.

Estou agora "jubilado", como dizem em espanhol. Vivendo a minha aposentadoria com a minha esposa, reunimos nossas forças restantes em Montreal, junto aos nossos filhos e netos.

Hervé Breton: Pode-se dizer que já entramos em uma reflexão sobre o tempo em dois níveis. Você já temporalizou ou periodizou a sua trajetória e, ao mesmo tempo, está situando uma série de produções ou trabalhos que a marcaram, especialmente o doutorado. Antes de abordar as suas obras, como você procedeu para periodizar os trabalhos? Pode-se pensar que é algo natural, mas estas divisões temporais foram produzidas por você. Você saberia dizer como procedeu para identificar esses grandes períodos?

Gaston Pineau: Trata-se de reduzir ao essencial. Ainda é um pouco padrão em qualquer currículo. Por outro lado, quando me aposentei, tive a sorte de ter uma operação de co-biografização extremamente interessante. Uma colega, Christine Abels-Eber, coordenou toda uma operação de co-biografização. Ela 
pediu a mais de vinte pessoas com quem eu trabalhei para escrever a história do tempo de trabalho comigo e também fez uma entrevista autobiográfica comigo durante uma das minhas viagens. Além disso, pediu-me para reagir ao que os 28 colegas disseram a meu respeito, o que resultou no livro "Gaston Pineau: trajet d'un forgeron de la formation, regards croisés de compagnes et compagnons de route" - Gaston Pineau: trajetória de um ferreiro da formação, olhares cruzados de companheiros e companheiras de estrada (ABELS-EBER, 2010). Desejo que todos possam se beneficiar desse trabalho, que permite um retorno reflexivo de cada um não só em direção à própria reflexão, mas também à reflexão dos companheiros e das companheiras de estrada, que são extremamente esclarecedores e integradores.

Por exemplo, na minha autobiografia, há três períodos principais. Comecei com a entrada franco-quebecois na vida profissional (1965-1985). Continuei através dos anos de juventude, entre a forja, a vinha e o engajamento, desde meu nascimento em 1939 até 1965.

Depois veio o período tourangelle ${ }^{1}$ entre 1985 e 2007, seguido pela transição para a jubilación (aposentadoria) em 2007.

Na primeira parte, sobre os olhares cruzados, assinalo - já que existe uma importante dimensão brasileira - que há um capítulo inteiro sobre a "Gênesis brasileira e portuguesa", feito por três pessoas. Sou particularmente sensível ao "Tempo das gênesis, tempo de tornar-se, tempo do futuro", de Maria de Conceição Passeggi, porque ela vem de Natal e ela me inspirou muito. Sobre as casas familiares rurais, Thierry de Burghgrave escreveu: "Gaston Pineau, este novo nômade moderno dos itinerários formativos". De fato, tivemos um importante mestrado em "formação e desenvolvimento sustentável" em parceria com o Brasil (PINEAU et al., 2009). Há também um texto de Maria do Loreto Paiva Couceira, de Portugal, com quem tenho trabalhado muito.

Portanto, há este olhar retrospectivo e coletivo que eu realmente desejo a todos durante um período de transição para a aposentadoria.

Hervé Breton: Gostaria de voltar à sua tese de doutorado intitulada "Temporalidade e formação". Esta é sua primeira grande produção sobre a questão do tempo no campo da educação de adultos?

Gaston Pineau: Sim e não. Foi um pouco como a autorização para orientar pesquisas que você está postulando. É uma retrospectiva sobre produções passadas que tem uma função de síntese, o que faz surgir conexões que você não vê no momento.

1 Referente aos arredores da cidade de Tours, França. 
A responsabilidade pela pesquisa em educação permanente abriu um campo imenso. Foi a queda do muro escolar da educação e uma abertura para o tempo infinito, quando se pensou que a educação havia parado na infância e na adolescência e havia sido reduzida à pedagogia, à conduta das crianças. Então, nos encontramos diante de um faroeste. Encontrei um reitor proeminente que me disse: "Se eu quiser que você encontre alguma coisa, é você quem decide o que procurar". Ou seja, liberdade total.

Isto foi nos anos 70, época de Paulo Freire e Ivan Illich. Buscávamos não reproduzir a escola, não tornar a educação permanente uma perpetuação segundo um modo simples de reprodução. Fácil de dizer, mas menos de fazer.

Nessa época, lancei duas oficinas: uma teórica e uma global sobre os textos que esboçaram o que poderia ser a educação permanente. Eles foram mais ou menos inspirados por Ivan Illich (1970) e Paulo Freire (1967). Mas estes textos eram dispersos e marginais. Muitos deles ainda faziam parte da literatura cinzenta e pouco socializada. Um importante reagrupamento reflexivo se impôs. Realizei uma pesquisa bibliográfica sistemática, complementada por intervenções de pessoas pioneiras quando ainda estavam vivas.

A primeira oficina gerou meu primeiro livro intitulado "Éducation ou aliénation permanente? Repères mythiques et politiques" (Educação ou alienação permanente? Indicadores míticos e políticos, 1977), que me iluminou muito. Descobri que Platão, com o mito da caverna, propôs, cinco séculos antes da nossa era, um dos modelos mais bem construídos de educação permanente, alternando experiências práticas imersas na vida mundana, no claro e escuro da caverna, com visões teóricas iluminadas pelo sol. Ele a chamou de circuito longo, em oposição ao circuito curto da Academia que ele havia fundado, que já revelava os limites de uma educação ligada apenas às idades iniciais da vida. Henri Desroche escreveu um excelente capítulo sobre a origem utópica pré-moderna desta perspectiva de aprendizagem ao longo da vida e em todos os setores da vida. Então, a partir da segunda metade do século XX, vieram os discursos dos promotores das correntes internacionais, americanas e europeias. Depois vieram os discursos de institucionalização e os discursos críticos. E finalmente os discursos da especificação atual, lutando com este horizonte temporal infinito. Ele recua quando avançamos. Mas nos permite avançar e permanecer caminhando.

A segunda oficina foi mais operacional. Como estávamos a serviço da educação permanente, tivemos que ser autofinanciados e, portanto, criar programas para fazer a junção entre o que chamamos de necessidades da educação de adultos (profissionalização, conscientização) e os recursos universitários. Havia uma necessidade de novas ligações entre novas necessidades e novos recursos. Este foi o início da engenharia de formação e dos diferentes tipos de acompanhamento para conceber, construir e conduzir novas estratégias e novos caminhos de formação. 
Fiz minha primeira tese sobre este aspecto: "Rôle et système nouveaux en éducation. Essai d'application d'une approche systémique à l'analyse d'un service universitaire d'éducation permanente" (Os novos papéis e sistemas em educação. Tentativa de aplicar uma abordagem sistêmica à análise de um serviço universitário de educação permanente, 1973).

Ela foi publicada sete anos depois com o título "Les Combats aux frontières des organisations. Un cas universitaire d'éducation permanente" (Os combates nas fronteiras das organizações. Um caso universitário de educação permanente, 1980). Estávamos realmente na fronteira entre a universidade e os movimentos sociais. Tínhamos, portanto, que encontrar pontos de articulação.

No final dos anos 70, uma pessoa que trabalhava sobre alternância, interrogou-me sobre a minha experiência de vida. Na verdade, eu não me formei de forma linear, mas através da alternância entre uma vida de trabalho, sem trabalho e com viagens. Foi esta entrevista que me trouxe de volta ao interesse das histórias de vida para começar a compreender seu percurso, sua trajetória.

Mas estas oficinas representavam três setores distintos. Eu não via nenhuma conexão entre elas. Quando tive a oportunidade de fazer minha tese, primeiro tive que encontrar um fio condutor comum, ao menos que fosse pelo título. O primeiro que encontrei foi um fio epistemológico: como passar de uma abordagem positivista para uma abordagem dialética? A abordagem dialética tradicionalmente torna possível lidar com as contradições do tempo. Mas eu teria que me trancar em uma biblioteca por cinco anos para passar por tudo isso. Foi quando, encurralado, eu disse a mim mesmo que o elo era o tempo. O elo entre os meus campos de trabalho "Educação ou alienação permanente" (1977), "Combates nas fronteiras das organizações" (1980), "Produzir sua vida: autoformação e autobiografia" (1983), era a temporalidade. Eu não podia mais voltar atrás e fui, então, obrigado a me jogar neste oceano, porque não há nada mais invisível e móvel do que o tempo. O título da tese de doutorado foi então "Éducation permanente et temps" (Educação permanente e tempo, 1984). Ela unificou as minhas oficinas e permitiu-me tecer uma história com elas, trazendo para mim um fio cronológico horizontal e diacrônico e um fio vertical e sincrônico de cadeia, segundo o paradigma da tecelagem, epistemologicamente ligado à construção da história (PAUL, 2003). As oficinas continuaram.

A passagem para o ano 2000 não foi apenas uma passagem qualquer. Não só houve uma passagem de ano, do centenário, mas também do milênio. Eu quis marcar esta passagem refazendo uma síntese de todo o meu trabalho sobre o tempo desde 1986. Isso havia sido há 15 anos. Tirei então uma licença sabática de seis meses que me permitiu escrever "Temporalités en formation. Vers de nouveaux synchroniseurs" (PINEAU, 2000, Paris, Anthropos), traduzido para o Brasil em 2004: "Temporalidades na formação: rumo a novos sincronizadores" (São Paulo, Triom). 
Hervé Breton: Há a tese "Tempo e contratempo" em 1986? Em seguida a tese de Estado foi em que ano? Seria a mesma?

Gaston Pineau: Naquela época, existiam duas teses. A tese de terceiro ciclo (1973), "Les Combats aux frontières des organisations" (Os combates nas fronteiras das organizações), foi mais operacional. Levei sete anos para publicála. Foi desenvolvida segundo uma abordagem sistêmica. Naquela época, não estava muito desenvolvida e só fui entender isso cinco ou seis anos mais tarde. Eu defendi esta tese na Sorbonne, com Joffre Dumazedier.

Para fazer minha tese de Estado, não conseguia encontrar ninguém com quem eu tivesse interesse em trabalhar, até que eu encontro Georges Lerbet, que me disse: "Com toda a sua produção, você pode fazer uma tese de Estado sobre os seus trabalhos". Isso foi em 1984 e originou o trabalho "Éducation permanente et temps" (Educação permamente e tempo), publicado pela primeira vez em 1987 com o título "Temps et contretemps" (Tempo e contratempo). Foi então revisada e concluída em 2000, com o título "Temporalidades na formação: rumo a novos sincronizadores".

Hervé Breton: De que forma o tempo apareceu como um sincronizador ou um elemento ligando os três temas previamente nomeados?

Gaston Pineau: De certa forma, o tempo é um dessincronizador. É melhor falar sobre as temporalidades. O tempo, no singular, de fato, esconde múltiplas temporalidades que rompem nesta bela e aparentemente simples unidade. Queremos encontrar um tempo universal quando de fato somos trabalhados por temporalidades plurais e contratempos. A definição de tempo que me ajuda é novamente a de Aristóteles: "É a medida do movimento" (Physique, IV, 11.219 b 1-2). O tempo é constituído por movimentos invisíveis e múltiplos.

Podemos tomar o termo "medida" no sentido cronométrico, que é a definição de tempo universal, que consiste em dividir tudo em unidades homogêneas; ou, no nível musical, no sentido de "medida rítmica". De fato, para resumir, na educação de adultos, queremos passar de uma época que obedece à religião do relógio para a construção do ritmo a partir das diferentes temporalidades. Por esta razão, o artigo "Conjuguer les temporalités pour en faire des rythmes formateurs" (Conjugar temporalidades para fazer ritmos formativos, PINEAU, 2018) com tempos e contratempos, representa uma síntese importante. Existe, entre outras coisas, a ideia de adquirir uma competência temporal chave, que seria a competência da formação que consiste em ritmar os tempos de formação. Trata-se da competência ritmo-formadora. Trata-se de ritmar os tempos e contratempos em movimentos formadores de si. 
Hervé Breton: O que você está apontando seria um gesto de apropriação desses ritmos?

Gaston Pineau: Presto aqui minha homenagem a um pioneiro português e brasileiro, Lucio Alberto Pinheiro dos Santos. Em 1931, ele escreveu um livro completamente desconhecido, La ritmanalise. Ele inspirou bastante Bachelard (1963) e Bachelard me inspirou muito. Ele diz que o ritmo é a única maneira de unificar temporalidades contrárias, os tempos e contratempos, tempos longos e curtos. O ritmo cria unidade com opostos. Mas quais ritmos? Por exemplo, o ritmo cósmico ritma o nosso tempo humano, apesar de tudo. Não é apenas o tempo dos relógios. Uma hora da meia-noite não é uma hora meio-dia. Uma hora de manhã não é uma hora da madrugada, mesmo que aparentemente seja homogênea. Portanto, há movimentos mais importantes que dão ritmo aos outros. Daí a noção de sincronizador. Os músicos estão bem cientes de que, em algum momento, há aquele que dá a medida e sincroniza os diferentes músicos. $\mathrm{O}$ truque é encontrar o sincronizador para substituir o alinhamento do relógio, a religião do relógio que dá um ritmo uniforme, entre outras coisas, o tempo escolar. Temos que fazer tudo durante uma hora de aula, uma hora homogênea.

Trata-se, portanto, de substituir este sincronizador mecânico do tempo horário por outros. $\mathrm{Na}$ verdade, existem práticas que nos permitem viver aplicando ritmos que não o do relógio. Existem práticas rítmicas de reflexo natural. Em um dado momento, a pessoa nasce porque o ritmo biológico do feto está suficientemente assegurado para tornar o embrião autônomo que pede para sair e, ao sair, consegue, através de seu ritmo respiratório, sobreviver, desligado da sua mãe.

Existem, portanto, práticas que, felizmente, asseguram conexões rítmicas vitais entre o corpo e o meio ambiente. É uma questão de encontrar as principais práticas e pensar nelas a fim de transformá-las em estratégias. Esta manhã, você deve ter feito sua meditação. Você encontrou uma maneira de fazer deste ritmo dia-noite o seu próprio ritmo sem ir a toda velocidade, reflexivamente, porque é a hora do dia.

Após certo número de pesquisas, surgiram três práticas naturais que devem ser transformadas em prática pessoal. O primeiro é o tempo diário dia-noite, repouso-atividade. Como podemos vivenciar isso? O cotidiano pode ser um momento importante de formação ou de deformação. Pode ser completamente entorpecido pelo fato de ser repetitivo. Como podemos transformá-lo em um ritmo formador?

Há um tempo um pouco mais longo com as histórias de vida. Quando encontramos um amigo, ele diz: "Então? O que você tem feito?". Começamos, então, a contar sobre uma parte da nossa vida para atualizá-lo. A narrativa da 
vida desenvolve uma prática natural de fazer um balanço de tempos em tempos. A história de vida ou a linguagem da própria vida é um possível sincronizador deste tempo e um contratempo vital para torná-lo nosso, para conquistar seu tempo.

Há também a alternância, que é mais desenvolvida institucionalmente. $\mathrm{O}$ tempo escolar só é interessante se for vivido através de tempo não escolar, através de experiência não escolar. Na maioria das vezes, é um ritmo de trabalho-estudo. Agora, é feita uma distinção entre educação formal e informal ou não formal. Há vinte anos, só havia educação formal. A alternativa pode ser um sincronizador e um meio de se apropriar dos tempos e contratempos da vida (PINEAU, 2019).

Hervé Breton: Se voltarmos à vida diária, que tipo de práticas contribui para encontrar um ritmo na escala da unidade dia-noite? Quando se fala de histórias de vida, fica claro que a prática da apropriação passa pela linguagem, pela narração. Quanto à alternância, podemos quase imaginar as questões de engenharia ou de dispositivo. Com relação à experiência quase imediata do tempo vivido na escala do dia, quais são as práticas?

Gaston Pineau: Você está certo. É a prática mais difícil de se construir e nunca é completamente adquirida. O cotidiano é infra linguístico. São as atividades alimentares e fisiológicas que primam (dormir, descansar, fazer, comer, respirar). São realmente as atividades fisiológicas básicas que impõem suas leis, às vezes de uma forma tão dominante que elas entorpecem. Estamos reduzidos a um vegetal. Levantamos porque temos que nos levantar, comemos porque estamos com fome. E é a repetição infinita e reificada. Por muito tempo, eu mantive isso fora da história de vida. Era muito repetitivo. Não havia eventos que se sucediam nesse contexto. Não havia o que pensar. É por isso que é necessária uma análise hermenêutica muito diferente e muito particular para explorar estes fenômenos infra-conscientes.

Neste ponto, se quisermos nos situar em termos de educação, este aprendizado não pode ser ensinado, ele pode ser aprendido através de um processo iniciático com os três grandes momentos presentes em qualquer processo desse tipo: ruptura, transição e integração. Tomemos o exemplo da aprendizagem da noite. Diz-se que o cotidiano dura 24 horas. Isso é tudo o que há. Há sempre os mesmos 60 minutos. Mas, na verdade, as horas noturnas não são vivenciadas da mesma forma que as horas diurnas. Descobrir como vivemos as horas noturnas, demanda quase desaprender, deixar os óculos do dia. O noturno é o não-visual, é o desaparecimento do sentido da visão. Por outro lado, os sentidos de proximidade (olfato, audição, paladar) tornam-se mais fortes. Para provar algo, às vezes fechamos os olhos para nos concentrarmos nas sensações gustativas quase imperceptíveis. 
Minha primeira experiência de aprendizado das 24 horas foi romper com as horas do dia para tomar consciência das horas da noite. Você entra na fase de transição onde você se pergunta o que está acontecendo. Ao anoitecer, há perdas. $\mathrm{O}$ que acontece às 22 horas e às 23 horas? Quanto mais avançamos na noite, mais o contato social é reduzido e mais você se encontra sozinho - seja completamente sozinho ou com uma outra pessoa muito próxima. À meia-noite, os centros de concentração estão embaçados. Você realmente não sabe mais onde está. Dizem, muito frequentemente, que as horas mais difíceis são as 2 ou 3 da manhã. É um intermédio. É o dia que começa a chegar.

Portanto, primeiro foi necessária uma fenomenologia da noite. Nisso, também, o Bachelard me ajudou muito. Ele é um grande explorador. Ele vê essa dinâmica como uma maré crescente e decrescente. Lembro-me de que parei a primeira análise fenomenológica da noite às 5 horas da manhã porque estava exausto. Foi aí que a autoformação entrou. $\mathrm{O}$ polo dos outros se desvanece e há algo quase fisiológico, algo sensível vindo à tona. É o lar organizacional invisível. É invisível e se organiza sem que saibamos como, o quê, com, quando... os fantasmas, os sonhos não estão em ordem. Tudo vem à tona. Trata-se de uma nova unidade microcósmica que se estabelece.

Conduzi a primeira análise fenomenológica no final dos anos 80 graças à UNESCO e a Paul Lengrand que explorou as principais áreas da educação ao longo da vida: tempo, espaço, trabalho, lazer, cultura: "Educação ao longo da vida e tempo", em Paul Lengrand (ed.)1986, Areas of Learning Basic to Lifelong Education (Áreas de Aprendizagem Básica para a Educação ao Longo da Vida). Ele me pediu para cuidar do tempo. Eu havia mergulhado em todas as grandes filosofias sobre o tempo, mas eu não sou filósofo, eu me perdia. Então perguntei-me o que significava educação permanente em termos de uma unidade curta, de 24 horas. Muitas vezes a levamos ao nível da vida. Mas isso significa algo circunscrito a uma unidade curta? Foi aí que a noite chegou.

Eu tinha feito, então, minha primeira análise. Eu tinha parado, exausto, às 5 da manhã. Quando reeditei o livro “Temporalidades em Formação”, em 2000, retomei esta análise. Foi quando eu cheguei ao despertar. O despertar concentra movimentos extraordinários de emergência, de pré-consciência. Muitas vezes, reduzimos as abordagens psicanalíticas ao consciente e ao inconsciente, enquanto que há a zona do subconsciente que você explora muito, especialmente com Pierre Vermersch, que acaba de nos deixar. Ele foi o grande explorador deste nível de subconsciência. O que é que começou nesse momento? Como podemos prestar atenção a isso?

Acho que o despertar é importante. Em primeiro lugar, há uma chegada ao subconsciente. Estamos aqui, mas não temos certeza do que vamos fazer. As coisas surgem, elas mais ou menos fazem você querer se levantar. E, em algum 
momento, uma decisão é tomada, dizemos a nós mesmos: "Isso me interessa. Vale a pena despertar". Mas este aprendizado - ou iniciação - ao movimento de 24 horas é infinito. Você aprende um pouco sobre as horas noturnas, mas depois tem que articulá-las com o dia. O que é importante? São os sonhos da noite que queremos realizar durante o dia? Ou é a ordem do dia que diz que você tem que guardar os sonhos para si mesmo? O que tem precedência sobre as agendas do dia e as intuições da noite?

Hervé Breton: Aqui estão algumas coisas para se pensar na escala de 24 horas. Nas histórias de vida, há diferentes unidades de tempo? Não é apenas a existência? Como isso poderia ser caracterizado? Trata-se de outra apreensão de tempo? Menos dentro do imediatismo?

Gaston Pineau: Durante muito tempo, eu vi a vida cotidiana como diferente das histórias de vida. "Le quotidien: un haut lieu de formation/déformation humaine" - Vida cotidiana: um lugar privilegiado de formação/deformação humana (PINEAU, 2014). Agora, estou começando a trabalhar em histórias de vida em três velocidades, retomando a noção de Braudel de três velocidades (PINEAU; LE GRAND, 2019), Les histoires de vie, Paris: PUF, p. 89-90; no Brasil, 2012, As histórias de vida, Natal: Edufern). Há movimentos individuais que são temporalidades curtas. Os historiadores dizem que é realmente muito curto para ser interessante. O que os mobiliza são as temporalidades sociais em velocidade média. E existem temporalidades longas, planetárias. Os historiadores dizem que somente o tempo social é interessante. As temporalidades pessoais são muito curtas e as temporalidades longas são muito longas.

Os historiadores também estão passando por uma crise paradigmática. Com as histórias de vida, chegou o tempo pessoal curto. Há um debate entre psicólogos e sociólogos: estes são tempos psicológicos, mas o social é ignorado. De fato, podemos ver que o tempo psicológico é articulado com o tempo social. Em grande parte, a história da vida não deve ser reduzida ao tempo social, mas deve conquistar seu tempo também. Os dois tempos estão começando a se tornar explícitos.

À medida em que envelhecemos, temos menos tempo sócio profissional. Estamos mais envolvidos com os tempos de vida pessoais, intergeracionais, mas também cósmicos: dia/noite; estações... Nesse momento, acho que a história de vida em três velocidades deve envolver o tempo longo que é paradoxal. É macrocósmico não apenas na escala das estações, de um ano, mas também de períodos e, ao mesmo tempo, microcósmico. De fato, com os biorritmos, percebemos que o macrotempo cósmico tem uma influência microcósmica em nossos ritmos biológicos. 
Por exemplo, hoje, quando eu estava pensando na entrevista, era manhã. No Quebec, na América do Norte, era de manhã. É um microtempo cotidiano que volta novamente. Fizemos alusão ao tempo de meditação. Muitas vezes é pela manhã. Trata-se de tomar consciência de que esta hora da manhã nos conecta aos grandes movimentos cósmicos. As grandes orações dos nativos americanos me vieram à cabeça novamente. Tem-se a saudação para o sol nascente, para o grande Espírito: "Nós te homenageamos pelo sol nascente". É o momento da criação, do nascimento e do renascimento. Inscrever isso em uma história é a coisa mais difícil para mim. Como inscrever meu tempo cotidiano em um ritmo histórico?

Essa é uma questão importante para a terceira idade, pois os tempos sócio profissionais não existem mais. Se não conseguimos simbolizar, religar nosso tempo cotidiano ao tempo cósmico, reduzimos o campo da consciência, ele se restringe. Através do eu autobiográfico, António Damásio é categórico a este respeito. Ele diz que o campo da consciência se restringe aos gestos imediatos, enquanto que, se quisermos que ele se amplie, devemos abri-lo a ritmos cósmicos (DAMASIO, 1999).

Hervé Breton: Volto à definição proposta por Aristóteles de "a medida do movimento", que talvez se refira à questão da duração. Para o espaço, há uma noção que é de Gibson (1979), se não me engano, que leva o nome de "affordance". O autor fala sobre o acoplamento entre a percepção do espaço e o modo de ação do sujeito. Na teoria das três velocidades, há a questão da estimativa da duração para a realização de um tipo de ação ou fenômeno. Faz parte de um trabalho de formação saber como apreender, de fato, as durações relativas à realização de movimentos que atravessam o cotidiano ou a existência?

Gaston Pineau: Obrigado, Hervé, por introduzir a noção de espaço-tempo. Não se pode separar os movimentos do espaço, do espaço físico e do espaço social. A clivagem entre tempo/espaço, quantidade/qualidade é um traço da influência positivista. É uma divisão que temos que enfrentar porque o tempo é espaço-temporal. Está sempre ligado, para nós, a um lugar espacial e a um lugar social. O espaço-tempo é uma questão preponderante.

Quanto à duração, se falamos tanto de "sustentável" hoje em dia, é porque estamos cientes dos limites do instantâneo. Como podemos construir duração com instantes? Bachelard disse que é mais difícil explicar a duração a partir da descontinuidade dos nascimentos do que a partir da continuidade dos momentos ou movimentos. Esse é o desafio.

A história de vida consiste em tentar construir uma vida sustentável, mas também viável em espaços-tempos em movimento, com momentos e idades que 
devem ser articulados, conjugados, colocados juntos, ganhando sentido entre si, entre os outros e as coisas. Esse é o desafio da formação permanente ao longo dos tempos. Levantá-lo ao ponto de incluir a morte nas histórias de vida é um dos maiores problemas bioéticos de nosso tempo.

Dedicamos um livro inteiro a esta edição: "Histoires de morts au cours de la vie" - Histórias dos mortos ao longo da vida (SCHMUTZ-BRUN; LANI-BAYLE; PINEAU, 2011). O trabalho nestas fronteiras entre morte e vida está no centro da pesquisa de cuidados paliativos (ALVES, 2019; GALLÉ-GAUDIN, 2014).

Este curso não é, portanto, uniforme e as idades ainda menos. E o principal problema hoje é compreender isto e empreender uma formação permanente das idades e de seus cursos. Herdamos uma divisão educacional em três faixas etárias: a primeira infância e adolescência agrupadas sob a responsabilidade primária dos pais e professores. A educação deveria parar por aí, suficiente para a idade adulta e ainda mais para a terceira idade, que só tinha que aplicar o que havia sido ensinado e depois descansar. Esse legado ainda está muito vivo e condiciona fortemente nossas visões e práticas na vida adulta e pós-adulta. As formas de viver atualmente estão em meio a uma efervescente explosão revolucionária, tanto em termos de vidas no trabalho, quanto em termos de vidas emocionais, espirituais, culturais e intelectuais (PINEAU, 2000, 2004, cap. 7).

De acordo com abordagens transdisciplinares da educação para nossa era global (MORIN, 1999; MORAES; ALMEIDA, 2012), o primeiro conhecimento é reconhecer e superar esta cegueira paradigmática de uma pedagogia escolar herdada. A pesquisa sobre as histórias de vida em formação ao longo dos tempos, a alternância e o cotidiano nos levou a desenvolver, na dinâmica da caverna de Platão e dos três mestres educacionais de Jean-Jacques Rousseau (1762) - o eu, os outros e as coisas -, uma teoria de formação permanente em duas etapas - experiencial e formal - e três movimentos: auto, sócio e eco formação (PINEAU, 2000; 2004, cap. 10).

Na primeira idade até os 16, 18 ou 21 anos, dependendo do país, a educação das crianças é responsabilidade legal dos pais e professores, ou seja, outras pessoas com um status sócio hierárquico superior. Falamos então de heteroformação, uma forma de socioformação com os outros; o segundo sendo a co-formação, em reciprocidade com outros do mesmo status, amigos e camaradas.

Chegar à idade adulta é tornar-se responsável, entre outras coisas, pela sua própria formação, apropriar-se desta função, exercê-la com plena responsabilidade, passar a um regime de autoformação. Esta transição não é tão automática quanto a mudança de idade. Esta autonomização formativa leva tempo, muito tempo. E evolui em permanência por muito tempo. O período desde a idade adulta até a aposentadoria é de pelo menos 40 ou 50 anos, a metade da vida. 
Então, a chegada da aposentadoria é um momento muito forte, porque toda a autonomia sócio profissional, que serviu para nos construir de forma autônoma, vai embora. A força física diminui e, portanto, a autonomia. É o ambiente físico e as coisas que se impõem. Se há dois ou três degraus para subir, olhamos para o que está acontecendo, enquanto antes, costumávamos saltar com os dois pés. O polo físico, o eco formador ou eco deformador do ambiente físico torna-se mais importante. Devemos articular e ajustar a autonomia adquirida desta nova polaridade. E com o aumento da expectativa de vida, a terceira idade se estende até a quarta e até a quinta idade. Se a perda de autonomia do movimento físico e social não for compensada por um ganho de formação simbólica, o mundo pessoal se torna cada vez menor. Esta formação simbólica não é puramente imaginária. Ela cria novas conexões, novas comunicações e até mesmo comunhões entre coisas e pessoas, entre nosso microcosmo e o macrocosmo. A sabedoria dos antigos não é necessariamente anacrônica. Bachelard (1971) fala de autocosmogenia. O desafio da formação permanente é construir o próprio mundo conquistando o próprio tempo. Não se tem uma vida inteira para construir o próprio mundo, para se colocar no mundo (HENNEZEL; VERGELY, 2010).

Hervé Breton: Para finalizar, gostaria de lhe pedir para falar um pouco sobre as pesquisas contemporâneas, ou atuais, voltadas para a ligação entre o tempo ou a temporalidade e a formação. Quais são os autores e as obras que você julga importantes destacar e que foram publicados recentemente?

Gaston Pineau: Você me deu o livro de Rosa sobre aceleração (2013). Uma excelente revisão do tempo social. É verdade que é o movimento dominante. Mas a Covid nos força a desacelerar. Ela mostra como a medida do movimento social não é necessariamente a única. Seu outro livro sobre ressonância (ROSA, 2018) me inspira mais. Ele assume as diferentes esferas de relacionamento no mundo.

Estou pensando mais especificamente no Brasil com Boaventura de Sousa Santos $(2010,2016)$. Ele fala sobre as epistemologias do Sul. Isso é importante para contrabalançar as temporalidades homogêneas que vêm principalmente do Norte. Diz-se que a medida do tempo é a medida do poder. Aquele que consegue impor sua medida de tempo, consegue dominar o outro. Uma grande parte da colonização do mundo foi feita através da imposição de uma temporalidade do Norte que queria se apresentar como hegemônica, enquanto isso levou, nas palavras de Sousa Santos, a uma repressão e negação de outras experiências temporais, experiências consideradas menos capazes. Para construir uma alternativa à globalização viável e sustentável, é necessário lutar contra um desperdício mortal de experiências temporais, pessoais e comunitárias, pois é a luta pela vida. Toda vida deve desenvolver sua temporalidade específica para viver, em detalhes e ao longo do tempo, como você tão claramente desenvolve 
em seu artigo (BRETON, 2020) e na edição 2020, que você acaba de coordenar, da revista Éducation Permanente sobre a narração da experiência vivida e do conhecimento experiencial. Muitas vezes é incognoscível. Mas se a pessoa pudesse mostrar e explicar as estratégias mais ou menos conscientes que usa para sobreviver, isso realmente enriqueceria nossa cultura. Sousa Santos é, portanto, importante.

Há também todas as abordagens epistemológicas e fenomenológicas. Há Natalie Depraz com Le Corps glorieux - O corpo glorioso (DEPRAZ, 2008). Existem abordagens realmente muito interessantes para aumentar a conscientização de todos esses movimentos microcósmicos e macrocósmicos. Caso contrário, corremos o risco de perdê-los completamente e de não sermos sustentáveis por muito tempo.

Outro trabalho de referência, o de Michel Alhadeff-Jones (2016) sobre a questão dos ritmos. Para mim, ele é o que faz uma das melhores sínteses atualmente sobre estas questões muito complexas. Ele leva em conta as temporalidades dos educadores franceses, brasileiros e norte-americanos. Eles pensam em temporalidades singulares e não homogêneas. Ele me fez tomar consciência de algo. Eu não conseguia entender a ligação entre momentos e movimentos instantâneos. E ainda assim, falamos de momentum. Na verdade, os movimentos são feitos de momentos. Entre outras coisas, os momentos vivenciais tornam-se movimentos de emancipação e autonomização somente se eles puderem ser iluminados por um momento de teorização. Dou graças por isso. Estou pensando também em Pascal Roquet (2013). Sua grade analítica para articular micro, meso e macro-movimentos, baseada nos movimentos simultâneos que podemos operar, é uma pista realmente interessante.

Hervé Breton: Chegamos ao fim da nossa entrevista. Desejaria acrescentar algo mais?

Gaston Pineau: O movimento brasileiro o (auto)biográfico é importante. Os brasileiros também estão comemorando este ano os cinquenta anos da alternância. Estes movimentos, que foram muito marginais e emergentes, são realmente portadores importantes do futuro. $\mathrm{E}$ devemos celebrar o $70^{\circ}$ aniversário da morte de Lucio Alberto Pinheiro dos Santos. Ele nasceu em Braga, em 1889, e morreu no Rio de Janeiro, em 1950, depois de, entre outras coisas, ter ensinado em Carangola, Minas Gerais, em 1927. Celebrar, em 2020, o 70 aniversário de sua morte, é trazer sua presença de volta entre nós e recolocar a alternância na cultura do ritmo... das epistemologias do Sul.

Hervé Breton: Muitíssimo obrigado, Professor Gaston Pineau. 


\section{RÉFÉRENCES}

ABELS-EBER, Christine. Gaston Pineau: trajet d'un forgeron de la formation. Regards croisés de compagnes et compagnons de route (coord.). Paris: L'Harmattan, 2010.

ALHADEFF-JONES, Michel. Time and the Rhythms of Emancipatory Education. Rethinking the temporal complexity of self and sociiety. New York, Oxon: Routledge, 2016.

ALVES, Camila Aloisio. L'approche biographique et la temporalité des soins palliatifs aux enfants malades chroniques: des apprentissages qui se tissent entre la vie et la mort. Cadernos de Pesquisa, São Luís, v. 27, n. 1, p. 381-399, 2020. Disponível em: http://www. periodicoseletronicos.ufma.br/index.php/cadernosdepesquisa. Acesso em: 31 ago. 2020.

BACHELARD, Gaston. La poétique de la rêverie. Paris: Puf, 1971.

BACHELARD, Gaston. La dialectique de la durée. Paris: Puf, 1963.

BRETON, Hervé. L'enquête narrative, entre durée et détails. Éducation permanente, Paris, $n^{\circ} 222$, p. 31-42, 2020-1. (Dossier Narration du vécu et savoirs expérientiels).

DAMASIO, Antonio R. 1999. Le Sentiment même de soi. Corps, émotions, conscience, Paris : Odile Jacob, 1999.

DEPRAZ, Natalie. Le corps glorieux. Phénoménologie pratique de la philocalie des pères du déserat et des pères de l'église. Louvain: Louvain-La-Neuve-Éditions de l'Institut supérieur de philosophie, 2008.

GIBSON, James J. The Ecological Approach to Visual Perception. Boston: Houghton Mifflin, 1979.

HENNEZEL Marie de; VERGELY, Bertrand. Une vie pour se mettre au monde. Paris: Carnets Nord, 2010.

ILLICH, Ivan. Une société sans école. Paris: Seuil, 1970.

FREIRE, Paulo. L'Éducation: pratique de liberté. Paris: Cerf, 1967.

GALLÉ-GAUDIN, Caroline. Penser la formation aux soins palliatifs. Entre repères relationnels et pratiques réflexives. Paris: l'Harmattan, 2014.

LENGRAND, Paul. Areas of Learning Basic to Lifelong Education (éd.). London: Pergamon Press, 1986.

MORAES, Maria Cândida; ALMEIDA, Maria da Conceição. Os Sete Saberes Necessários à Educação do Presente. Por uma educação transformadora (org.). Rio de Janeiro: Wak, 2012.

MORIN, Edgar. Les sept savoirs nécessaires pour une éducation du futur. Paris: Unesco, 1999. 
PAUL, Patrick. Formation du sujet et transdisciplinarité. Histoire de vie professionnelle et imaginale. Paris: L'Harmattan, 2003.

PINEAU, Gaston; LE GRAND, Jean-Louis. Les histoires de vie. Paris : PUF, 2019.

PINEAU, Gaston; PUIG-CALVÓ, Pedro. Histoire de vie avec l'alternance: la voie de recherche-formation en deux temps trois mouvements et le master Formation et développement durable au Brésil. Revista Brasileira de Educação do Campo, Tocantinópolis, v. 4, p. 1-28, 2019. (Dossiê Temático: 50 anos da Alternância no Brasil). Disponível em: https://sistemas.uft.edu.br/periodicos/index.php/campo/article/ view/7279. Acesso em : 31 ago. 2020.

PINEAU, Gaston. Conjuguer les temporalités pour en faire des rythmes formateurs. Éducation permanente, Paris, n 217, p. 9-21, 2018-4. (Rythmes et temporalités en formation).

PINEAU, Gaston. Le quotidien: un haut lieu de formation/déformation humaine. Dans. GALVANI, Pascal; MOISAN, André (coord). Revue Pratiques de formation/Analyses. Pratiques spirituelles, autoformation et interculturalité. Saint-Denis, nº 64-65, p. 79-99, 2014.

PINEAU, Gaston; LE GRAND, Jean-Louis. As histórias de vida, Natal: Edufern, 2012.

PINEAU, Gaston; BACHELART, Dominique; COUCEIRO, Maria Loureto; GIMONET, Jean-Claude ; PUIG, Pascal (coord.). Alternatives socio-éducatives au Brésil. Expérience d'un master, international. Paris : l'Harmattan, 2009.

PINEAU, Gaston. Temporalidades na formação: rumo a novos sincronizadores. São Paulo: Triom, 2004.

PINEAU, Gaston. Temporalités en formation. Vers de nouveaux synchroniseurs Paris: Anthropos, 2000.

PINEAU, Gaston. Temps et contretemps. Paris: Éditions Universitaires; Momtréal: Éditions Saint-Martin, 1987.

PINEAU, Gaston. Lifelong education and time”, in Paul Lengrand (éd.).1986, op.cit.

PINEAU, Gaston; MICHÈLE-Marie. Produire sa vie: autoformation et autobiographie. Paris: Édilig; Montréal: A. Saint Martin, 1983. (Collection [Ré]Èdition, 2012).

PINEAU, Gaston. Les Combats aux frontières des organisations. Un cas universitaire d'éducation permanente. Montréal: Sciences et culture, 1980.

PINEAU, Gaston. Éducation ou aliénation permanente? Repères mythiques et politiques. Paris: Dunod; Montréal: Sciences et culture, 1977.

ROQUET, Pascal; GONÇALVES, Maria José; ROGER, Lucie; VIANA-CAETANO, Ana Paula (coord.). Temps, temporalités et complexité dans les activités formatives et professionnelles. Paris : l'Harmattan, 2013. 
ROSA, Hartmut. Résonance, une sociologie de la relation au monde. Paris: La Découverte, 2018.

ROSA, Hartmut. L'accélération. Une critique sociale du temps. Paris: La Découverte, 2013. SANTOS, Boaventura de Souza. Épistémologies du Sud. Mouvements citoyens et polémique sur la science. Paris: Desclée de Brouwer, 2016.

SANTOS, Boaventura de Souza. Descolonizar el saber, reinventar el poder. Montevideo: Ediciones Trilce, 2010.

SANTOS, Lucio Alberto Pinheiro. A ritmanálise. Rio de Janeiro: Sociedade de Psicologia e Filosofia, 1931.

SCHNUTZ-BRUN, Catherine; LANI-BAYLE, Martine; PINEAU, Gaston. Histoires de morts au cours de la vie. Paris: l'Harmattan, 2011.

Texto recebido em 30/09/2020.

Texto aprovado em 07/11/2020. 